\title{
VENEI
}

\section{Mudança Tecnológica e Polarização do Emprego no Brasil}

\author{
Gabriella Rodrigues Rocha (UNIFESP); \\ Daniela Verzola Vaz (UNIFESP);
}

\begin{abstract}
resumo: Este estudo analisa a polarização do emprego no mercado de trabalho brasileiro em razão dos avanços das tecnologias digitais. A metodologia adotada é o Índice de Intensidade de Tarefas Rotineiras (RTI) proposto por Autor e Dorn (2013). O RTI foi aplicado ao setor da indústria de transformação, usando-se os microdados da Relação Anual de Informações Sociais para os anos de 2003, 2013 e 2018. Também foram analisadas as variáveis que influenciam a probabilidade de se desempenhar tarefas rotineiras, manuais ou abstratas, usando um logit multinomial. Observou-se que a maioria dos grandes grupos ocupacionais possui valores negativos de RTI, indicando que os empregos se encontram polarizados. Porém, entre 2003 e 2018 a intensificação da polarização foi baixa. Os resultados do logit multinomial apontam que as chances de desempenhar tarefas abstratas aumentam quando o trabalhador possui ensino superior, acumula mais experiência profissional e trabalha em empresas de médio porte.
\end{abstract}

palavras-chave: Progresso Técnico; Indústria 4.0; Mercado de Trabalho; Polarização do Emprego; Indústria de Transformação.

Área Temática: 2.3 Salários, emprego e divisão internacional do trabalho. 


\section{Introdução}

O desenvolvimento tecnológico pode causar múltiplas formas de ruptura, desde mudanças na demanda por qualificação da força de trabalho até mudanças na estrutura do mercado, com a necessidade de novos modelos de negócios, novos padrões de comércio e investimento, novas ameaças à segurança (digital) dos negócios e mais amplos desafios aos processos sociais e até políticos.

Ao longo dos tempos, desde a primeira e a segunda revolução industrial — importantes pela incorporação das máquinas e pela produção em larga escala —, até a revolução da informatização com a introdução das tecnologias de informação - houve importantes mudanças na estruturação do mercado de trabalho, resultando na extinção de algumas ocupações, por se tornarem defasadas, e criação de outras. Em 2011 foi cunhado o termo Indústria 4.0, que diz respeito às transformações causadas pela fusão de tecnologias que permeiam as esferas física, digital e biológica. Segundo Tessarini e Saltorato (2018, p. 743-744), "trata-se de um novo modelo de produção, em que máquinas, ferramentas e processos estarão conectados à internet através de sistemas cyber-físicos, interagindo entre si, e com capacidade de operar, tomar decisões e se corrigir praticamente de forma autônoma". Por sua grandiosidade, a Indústria 4.0 está sendo considerada a quarta revolução industrial, tendo como um dos seus principais impactos sociais a modificação nas relações de emprego.

O progresso inovativo tem um papel importante tanto para empresas quanto para países, tornandoos competitivos no ambiente capitalista. No entanto, o Brasil investe pouco em Pesquisa e Desenvolvimento (P\&D) em relação aos países desenvolvidos. Em 2018, o País ocupou a 64르 posição no Índice Global de Inovação (GII) ${ }^{1}$, em uma amostra de 126 países. O índice possui 80 indicadores que abrangem aspectos como ambiente político, capital humano, infraestrutura e sofisticação de negócios. No quesito desempenho do ambiente de negócios, o Brasil é bastante fraco, ocupando a 110 a posição.

O setor industrial brasileiro, apesar de estar perdendo participação no Produto Interno Bruto (PIB) nacional, é o 9o maior do mundo, de acordo com o World Economic Forum (WEF, 2018), e responde por aproximadamente 10\% do PIB. O Brasil é um dos principais destinos de investimentos estrangeiros diretos e investimentos em novas áreas, o que facilita a transferência de conhecimento e tecnologia. A Confederação Nacional da Indústria (CNI, 2016) afirma que no médio e longo prazo a incorporação das novas tecnologias é uma estratégia fundamental para o desenvolvimento da indústria e para a competitividade do País, sendo necessário que se incorpore com rapidez as tecnologias digitais, evitando que o atraso em relação a alguns dos principais países competidores aumente.

Apesar de, no Brasil, não haver oficialmente uma implementação da Indústria 4.0, existe uma pequena difusão dessas tecnologias, como aponta a pesquisa da CNI (2016), segundo a qual dentre 29 setores da indústria de transformação e extrativa, $48 \%$ possuem uma das onze tecnologias características da Indústria 4.0.

Cumpre notar, no entanto, que a capacidade da força de trabalho brasileira é limitada em conhecimentos digitais, engenharia, pensamento crítico e outras áreas. O desenvolvimento digital exige uma maior qualificação dos trabalhadores. Os trabalhadores não qualificados ou pouco qualificados são mais predispostos a sofrerem com os custos do desenvolvimento digital, perdendo seus empregos, uma vez que são mais propensos a não se adaptarem às novas tecnologias e a não se beneficiarem das novas oportunidades oriundas da transformação digital. Desse modo, a busca por uma inserção mais competitiva na economia mundial, por meio da Indústria 4.0, poderia ocasionar resultados danosos para a economia do País, como o aumento do desemprego e a intensificação da polarização do emprego, pois quanto maior o nível educacional, menor o risco de perda do posto de trabalho.

Para estudar os efeitos da informatização no mercado de trabalho, Autor, Levy e Murnane (2003) propuseram um modelo para explicar o que os computadores fazem no local de trabalho e como eles interagem com o trabalho humano, apresentando a hipótese de rotinização. Os autores explicam que a rotinização se apoia nas hipóteses de que o capital computacional substitui os trabalhadores na execução de um conjunto de tarefas de rotina e os complementa na execução de tarefas não rotineiras.

A partir dessa literatura, a polarização do emprego vem sendo observada em vários países, como nos Estados Unidos desde 1980 com os estudos de Acemoglu e Autor (2011) e Autor e Dorn (2013), no Reino Unido por Goos, Manning e Salomons (2014), na Espanha por Consoli e Sánchez-Barrioluengo (2018), em Portugal por Fonseca, Lima e Pereira (2018) e em dez países da Europa Central e Oriental por Keister e Lewandowski (2016). Além disso, Hardy, Lewandowski, Park e Yang (2018) encontraram

1 O Índice Global de Inovação é organizado pela Universidade de Cornell, pela Organização Mundial da Propriedade Intelectual (WIPO) e pela escola de negócios INSEAD. Disponível em: $<$ https://www.globalinnovationindex.org/analysis-indicator>. 
polarização em 42 países cobertos pelo Programme for the International Assessment of Adult Competencies (PIAAC) no período de 2012 a 2014. No Brasil a polarização do emprego tem sido evidenciada nos trabalhos de Soares Junior (2009), Bressan e Hermeto (2009), Olivieri (2016), Corseuil, Poole e Almeida (2018), Santos, Vaz e Oliveira (2019) e Sulzbach (2020).

Tendo em vista que as empresas brasileiras estão adotando algumas das tecnologias digitais típicas da Indústria 4.0, e dadas as evidências de polarização do emprego no país, este estudo tem como objetivo analisar se a adoção de tecnologias digitais tem intensificado a polarização do emprego no mercado de trabalho da indústria de transformação brasileira.

A metodologia empregada para a análise consiste no cálculo do Índice de Intensidade de Tarefas Rotineiras (RTI), proposto por Autor e Dorn (2013). O RTI é aplicado ao setor da indústria de transformação, usando-se os microdados da Relação Anual de Informações Sociais (RAIS) para os anos de 2003, 2013 e 2018.

Além do cálculo do RTI, são analisadas, por meio de um modelo logit multinomial, as variáveis que influenciam a probabilidade de um indivíduo desempenhar atividades rotineiras, manuais ou abstratas. Pretende-se, em particular, investigar como fatores como experiência profissional, escolaridade, tamanho da empresa, localização geográfica e sexo afetam a probabilidade de desempenhar determinado tipo de tarefa.

O presente trabalho está dividido em cinco seções, incluindo esta introdução. A segunda seção realiza a revisão da literatura. Na terceira, são descritas a metodologia para construção do RTI e a estratégia empírica para aplicação do logit multinomial. Na quarta seção os resultados obtidos na pesquisa são apresentados e discutidos. Por fim, na quinta seção, apresentam-se as considerações finais.

\section{Revisão de Literatura \\ 2.1. Polarização do emprego}

Autor, Levy e Murnane (2003) formalizam a teoria de que a rápida adoção da tecnologia de computadores nas empresas - devido ao declínio em seus preços reais - modificou as tarefas executadas por trabalhadores em seus empregos e a demanda por qualificação da mão de obra, conhecida como hipótese de rotinização. Os autores explicam que essa abordagem parte de uma série de observações intuitivas de cientistas sobre as tarefas que os computadores são mais adequados para realizar e como esses recursos complementam ou substituem as habilidades humanas no local de trabalho. Desse modo, a rotinização se apoia na hipótese de que o capital computacional substitui os trabalhadores na execução de um conjunto de tarefas de rotina e os complementa na execução de tarefas não rotineiras.

Assim, Autor, Levy e Murnane (2003) classificam as ocupações em categorias de tarefas rotineiras - que compreendem a execução de um conjunto limitado e bem definido de atividades que requerem repetição metódica de um procedimento fixo, podendo ser realizadas por máquinas seguindo regras programadas explícitas - e não rotineiras - que são aquelas cujos procedimentos são implícitos, não apresentando regras suficientemente compreendidas para serem codificadas e executadas por máquinas. Para realizar essa classificação, os autores consideram o conjunto de características ocupacionais, ou seja, habilidades e requisitos do trabalho, contidos no Dicionário de Títulos Profissionais (DOT) ${ }^{2}$ dos Estados Unidos (EUA). Por meio da técnica de análise de componentes principais, cria-se um índice que sintetiza a intensidade rotineira das ocupações. Então, as ocupações dos EUA, quando considerada sua classificação ao nível de agregação de três dígitos, são classificadas como rotineiras ou não rotineiras, a depender do score recebido. São considerados cinco tipos de habilidades na análise:

- Cognitivas de rotina: associadas a definir limites, tolerâncias ou padrões;

- Manuais de rotina: correspondentes à destreza dos dedos;

- Analíticas não rotineiras: relacionadas ao gerenciamento eletrônico de documentos e matemática, conhecido como GED MATH;

- Interativas não rotineiras: relativas à direção, controle e planejamento;

- Manuais não rotineiras: correspondentes à coordenação do olho, mão e pé.

Com o avanço dessa literatura, Acemoglu e Autor (2011) destacam a importância da diferenciação entre habilidades e tarefas para uma análise mais eficiente dos mercados de trabalho modernos e das tendências atuais. Assim, a partir da hipótese de Autor, Levy e Murnane (2003), Acemoglu e Autor

\footnotetext{
${ }^{2}$ O DOT contém uma descrição de todas as ocupações dos EUA, com informações sobre as características dos empregos coletadas no final da década de 1970.
} 
(2011) caracterizam o conteúdo da tarefa dos trabalhadores dos Estados Unidos utilizando os descritores da Occupational Information Network (O*NET). São consideradas as seguintes categorias:

- Tarefas rotineiras cognitivas: que são atividades como contabilidade e trabalho de escritório e são caracterizadas como de baixa qualificação.

- Tarefas rotineiras manuais: trabalhos repetitivos e de monitorização de linha de produção. Requerem baixa qualificação.

- Tarefas não rotineiras manuais: atividades que exigem reconhecimento visual e interação pessoal, como secretários e motoristas. Embora simples, exigem habilidades que não podem ser descritas em um conjunto de regras programáveis, como conhecer o seu próprio corpo, o trânsito da cidade, decifrar uma caligrafia rabiscada etc., não sendo, portanto, tarefas rotineiras. Requerem qualificação intermediária.

- Tarefas não rotineiras abstratas: exigem capacidade de resolução de problemas, intuição e criatividade, como um diretor de uma empresa. São tarefas que requerem alta qualificação.

Cabe ressaltar que outras classificações foram desenvolvidas em contraposição à de Autor, Levy e Murnane (2003), como a proposta por Marcolin, Miroudot e Squicciarini (2016). No entanto, essa classificação utiliza parte das informações da metodologia de Autor, Levy e Murnane (2003) para abordar a ligação entre o conteúdo rotineiro das tarefas e a dotação de habilidades da força de trabalho. Sendo assim, Marcolin, Miroudot e Squicciarini (2016) não conseguem cumprir o objetivo de se afastar da metodologia de Autor, Levy e Murnane (2003). Cumpre notar que as metodologias mais usadas na literatura são as de Autor, Levy e Murnane (2003) e de Acemoglu e Autor (2011).

\subsection{Evidências anteriores na literatura empírica nacional}

A partir da teoria de Autor, Levy e Murnane (2003), as preocupações com os impactos das mudanças tecnológicas no mercado de trabalho impulsionaram diversas pesquisas, que apresentaram evidências de polarização do emprego e dos salários, entre outros fatores, em vários países. No Brasil essa literatura foi abordada nos trabalhos de Soares Junior (2009), Bressan e Hermeto (2009), Olivieri (2016), Corseuil, Poole e Almeida (2018), Santos, Vaz e Oliveira (2019) e Sulzbach (2020).

Soares Junior (2009) verifica a capacidade do modelo apresentado por Autor, Levy e Murnane (2003) em explicar o efeito da difusão dos computadores na demanda por tarefas rotineiras e não rotineiras, no período entre 1985 e 2002. Para isso o autor mensura a demanda por cada tipo de tarefa em cada ocupação, utilizando as descrições da Classificação Brasileira de Ocupações (CBO) e os dados da Relação Anual de Informações Sociais. A classificação das ocupações segue a tipologia de Autor, Levy e Murnane (2003) e a padronização de Spitz-Oener (2006). A pesquisa constata o aumento na demanda por tarefas não rotineiras em função da adoção de computadores no mercado de trabalho brasileiro entre 1985 e 2002, confirmando as proposições de Autor, Levy e Murnane (2003).

Bressan e Hermeto (2009) investigam a polarização do mercado de trabalho brasileiro no período de 1983 a 2003 em ocupações que exigem processos tecnológicos versus ocupações não-substituíveis pela tecnologia. Os autores também investigam as diferenças de remunerações, administração de recursos tecnológicos e habilidades complexas entre homens e mulheres. Utilizando os dados da Pesquisa Nacional por Amostra de Domicílios (PNAD), são atribuídos scores às ocupações, classificando-as em grupos ocupacionais de acordo com a proposta de Autor, Levy e Murnane (2003). Os resultados confirmam a hipótese de polarização. Além disso, regressões quantílicas para salários mostram um prêmio associado a ocupações não rotineiras não manuais à medida que se transita para o topo superior da distribuição de rendimento.

Olivieri (2016) analisa as dinâmicas da diferença salarial entre homens e mulheres no Brasil, usando dados da PNAD, entre os anos de 2002 e 2013. A CBO é classificada seguindo as descrições de Funchal e Soares (2013), que, por sua vez, seguem a tipologia baseada em Autor, Levy e Murnane (2003). A autora constata que as mudanças na demanda por trabalho mudaram a distribuição de tarefas (sobretudo as não rotineiras) e seus retornos, diminuindo o diferencial salarial por sexo entre $2002 \mathrm{e}$ 2014.

Corseuil, Poole e Almeida (2018) estimam o impacto das tecnologias digitais sobre o conteúdo das tarefas das ocupações de empregos brasileiros. Através dos dados da RAIS para os anos de 1999 a 2006, os autores discriminam as ocupações da CBO por tipo de tarefa a partir de Acemoglu e Autor (2011). Os autores concluem que as indústrias intensivas em tecnologia localizadas em cidades com acesso antecipado à internet reduzem sua dependência relativa de tarefas manuais e rotineiras, e que a 
adoção de tecnologias digitais altera a composição de habilidades das indústrias e cidades em direção a tarefas cognitivas e não rotineiras.

Santos, Vaz e Oliveira (2019) analisam a evolução do prêmio salarial associado a trabalhadores em ocupações com diferentes níveis de requisitos de habilidades no mercado de trabalho brasileiro entre 2006 e 2016. A análise é feita à luz da teoria Skill Biased Technological Change (SBT). Utilizando a RAIS, os autores classificam as ocupações da CBO em tarefas seguindo a classificação de Oliveira et al. (2017), que, por sua vez, seguem a metodologia de Autor, Levy e Murnane (2003). Os resultados indicam uma crescente evolução do prêmio salarial para trabalhadores que desempenham tarefas não manuais e não rotineiras, tarefas que exigem habilidades cognitivas, analíticas e interpessoais, indo de encontro com o que aponta a teoria SBTC.

Sulzbach (2020) apresenta três ensaios sobre a polarização dos empregos e dos salários no Brasil. O primeiro analisa a desigual distribuição por sexo da crescente procura por trabalhadores altamente qualificados, investigando a importância das competências sociais na crescente probabilidade de mulheres trabalharem em um emprego bom ( good job) no mercado de trabalho altamente qualificado. A partir disso, a autora discrimina as ocupações da CBO seguindo a metodologia de Autor, Levy e Murnane (2003) e Deming (2017), usando os microdados da RAIS para os anos de 1994 a 2017. Os resultados mostram uma relação positiva entre as competências sociais requeridas nas ocupações e a proporção feminina observada. No segundo ensaio, Sulzbach (2020) apresenta a resolução do puzzle relativo à polarização dos salários no Brasil, propondo uma forma alternativa de analisar a polarização dos salários através da estimativa dos preços das tarefas (task price) utilizando dados de painel a nível individual e os índices de tarefas contínuos de cada ocupação. Nesse ensaio a autora argumenta que a classificação proposta por Acemoglu e Autor (2011) não é pertinente para o Brasil, pois a agregação de ocupações não se ajusta adequadamente à intensidade da tarefa, uma vez que a CBO foca mais na especificidade das funções ocupacionais do que nas competências por elas exigidas. Dessa forma, a partir dos dados da RAIS para os anos de 2002 a 2014, a autora utiliza índices contínuos para classificação de tarefas de ocupações, seguindo a mesma classificação do ensaio anterior. Os resultados mostram um aumento acentuado no retorno das tarefas cognitivas entre os dois períodos analisados (2002-2003-2004 e 20122013-2014), tendo o avanço do preço das tarefas manuais sido mais suave no mesmo período, e o retorno das tarefas de rotina não se alterado. Essas evidências sugerem a existência de polarização na estrutura salarial no Brasil, tal como observado em vários outros países. $O$ terceiro ensaio apresenta a tendência divergente nas mudanças de emprego ao longo da distribuição de salários entre os setores formal e informal, analisando o impacto do conteúdo das tarefas exigidas por cada ocupação na probabilidade de um indivíduo ser informal e na diferença salarial entre estes dois setores. A classificação das ocupações em tarefas foi a mesma utilizada no primeiro ensaio, mas a base de dados utilizada é a PNAD para os anos de 2003 e 2015. Os resultados mostram que a probabilidade de um indivíduo ser informal está positivamente correlacionada apenas com as exigências de tarefas manuais.

\section{Metodologia}

\section{1. Índice de Intensidade de Tarefas Rotineiras (RTI)}

O RTI foi desenvolvido por Autor e Dorn (2013) a partir da hipótese de rotinização e considerando as mudanças tecnológicas como endógenas. Os autores adotam o modelo de Acemoglu e Autor (2011), incorporando a implicação de que quando a elasticidade da substituição na produção entre o capital computacional e o trabalho rotineiro é maior do que a elasticidade da substituição no consumo entre bens e serviços, a trajetória decrescente dos preços dos computadores resulta em queda dos salários dos trabalhadores de baixa qualificação executando tarefas rotineiras, em relação aos salários dos trabalhadores de baixa qualificação executando tarefas manuais não rotineiras, enquanto os trabalhadores de alta qualificação permanecem na produção de bens, causando polarização do emprego. Ou seja, os autores partem da hipótese de que a polarização é resultado da interação entre as preferências dos consumidores (aqui os consumidores são os empresários, que demandam mão de obra para a prestação de serviços em suas empresas, e preferem a variedade em detrimento da especialização) e o custo decrescente de automatizar as tarefas rotineiras e codificáveis.

Assim, Autor e Dorn (2013) discriminam as ocupações em diferentes níveis de intensidade, agrupando essas medidas para criar uma medida resumida da intensidade da tarefa de rotina (RTI) por ocupação, calculada como:

$$
R T I_{k}=\ln \left(T_{k, t}^{R}\right)-\ln \left(T_{k, t}^{M}\right)-\ln \left(T_{k, t}^{A}\right)
$$


em que $T_{k, t}^{R}, T_{k, t}^{M}$ e $T_{k, t}^{A}$ são, respectivamente, as entradas de tarefa rotineira (R), manual não rotineira (M) e abstrata (A) em cada ocupação $k$ no ano $t$. Nessa medida, são criados grandes grupos ocupacionais, para os quais são analisados o impacto de cada tipo tarefa no valor do índice. O RTI aumenta de acordo com a importância das tarefas rotineiras em cada ocupação e declina na importância de tarefas manuais não rotineiras e abstratas.

O índice RTI assume valores baixos na parte inferior da distribuição de habilidades ocupacionais, em que geralmente predominam as tarefas manuais, e no topo da distribuição de habilidades ocupacionais, onde prevalecem as tarefas abstratas. A intensidade de rotina tem, assim, forma de U invertido na habilidade ocupacional. Assim, se a elasticidade da produção exceder a elasticidade do consumo, aumentam os salários dos trabalhadores de baixa qualificação em tarefas manuais em relação ao salário das tarefas rotineiras, aumentando os fluxos de trabalho de baixa qualificação para atender as ocupações na parte inferior da distribuição de habilidades ocupacionais, polarizando as caudas inferiores das distribuições de salários e empregos (AUTOR; DORN, 2013).

Desse modo, quando o RTI é negativo, as ocupações apresentadas são majoritariamente inerentes a tarefas manuais não rotineiras e/ ou abstratas, e quando ele é positivo, há maior número de tarefas rotineiras.

\subsection{Caracterização da Amostra}

A principal fonte de dados desta pesquisa é a Relação Anual de Informações Sociais (RAIS) para os anos de 2003, 2013 e 2018. A escolha de 2003 se justifica por ser o ano em que entra em vigor a Classificação Brasileira de Ocupações (CBO) versão $2002^{3}$. Adicionalmente, também se consideram as transformações econômicas da China nos últimos 30 anos, conhecidas como China shock. Essas transformações abrangeram não apenas o rápido crescimento econômico e a acumulação sustentada de capital, como também grandes mudanças na composição setorial da produção e uma crescente importância dos mercados e habilidades empresariais. $\mathrm{O}$ aumento da competitividade chinesa mudou a intensidade da competição por produtos dos demais países, levando a uma contração nas indústrias, particularmente naquelas sujeitas a uma maior exposição à importação. Muitas empresas faliram e as que sobreviveram tiveram reduções no emprego, sendo os trabalhadores de baixa qualificação os mais afetados. Para sobreviver, as empresas foram compelidas a ampliar seus investimentos em inovações de produto e processos. Nessas condições, o mercado de trabalho foi amplamente afetado, o que pode ter contribuído para a aceleração da polarização do emprego. Já a escolha do ano de 2018 deve-se ao fato de ser o último ano com dados disponíveis no período de desenvolvimento desta pesquisa. Assim, a comparação dos anos de 2003 e 2018 permite cotejar os resultados antes e após a emergência da Indústria 4.0, bem como do China shock. No entanto, devido ao fato de o cenário econômico do Brasil em 2018 ser de recessão, foi analisado adicionalmente o ano de 2013, pré-crise econômica.

A Indústria de transformação $0^{4}$ é o setor que mais investe em inovação, como aponta a Pesquisa de Inovação (PINTEC/ IBGE) de 2003 a 2017. O número de empresas que implementaram inovações em 2014 (41.850) aumentou 51,5\% em relação a 2003 (27.621), porém entre 2015 a 2017 essa trajetória de crescimento é rompida e o número de empresas que investiram em inovação cai (34.396) possivelmente devido à crise econômica vivida no país. Segundo a Confederação Nacional da Indústria (CNI), dentre

\footnotetext{
${ }^{3}$ A CBO reconhece, nomeia e codifica os títulos e descreve as características das ocupações do mercado de trabalho brasileiro. Sua estrutura básica foi criada em 1977, a partir do convênio com a Organização Internacional do Trabalho (OIT), e tem como base a International Standard Classification of Occupations (ISCO) de 1968. Com base na nova metodologia internacional publicada em 1988, a ISCO88, a CBO foi reformulada, e sua nova versão foi publicada em agosto de 2002, entrando em vigor na base de dados de 2003. É essa comparabilidade entre a CBO2002 e a ISCO88 que permite que seja feita a classificação das tarefas nas ocupações brasileiras.

${ }^{4} \mathrm{O}$ setor da Indústria de Transformação é representado por Fabricação de Produtos Alimentícios; Fabricação de Bebidas; Fabricação de Produtos do Fumo; Fabricação de Produtos Têxteis; Confecção de Artigos do Vestuário e Acessórios; Preparação de Couros e Fabricação de Artefatos de Couro, Artigos para Viagem e Calçados; Fabricação de Produtos de Madeira; Fabricação de Celulose, Papel e Produtos de Papel; Impressão e Reprodução de Gravações; Fabricação de Coque, de Produtos Derivados do Petróleo e de Biocombustíveis; Fabricação de Produtos Químicos; Fabricação de Produtos Farmoquímicos e Farmacêuticos; Fabricação de Produtos de Borracha e de Material Plástico; Fabricação de Produtos de Minerais Não-Metálicos; Metalurgia; Fabricação de Produtos de Metal, Exceto Máquinas e Equipamentos; Fabricação de Equipamentos de Informática, Produtos Eletrônicos e Ópticos; Fabricação de Máquinas, Aparelhos e Materiais Elétricos; Fabricação de Máquinas e Equipamentos; Fabricação de Veículos Automotores, Reboques e Carrocerias; Fabricação de Outros Equipamentos de Transporte, Exceto Veículos Automotores; Fabricação de Móveis; Fabricação de Produtos Diversos; Manutenção, Reparação de Instalação de Máquinas e Equipamentos.
} 
os 29 setores da indústria de transformação e extrativa, 48\% possuem uma das dez tecnologias características da Indústria 4.0. Assim, sendo a indústria de transformação fortemente atingida pela nova revolução industrial, restringiram-se as amostras apenas para essa classe da Classificação Nacional de Atividades Econômicas (CNAE) 2.0.

O universo de análise se restringiu a trabalhadores com idade entre 16 e 65 anos, com jornada de trabalho entre 30 e 44 horas semanais, celetistas com contrato de trabalho por tempo indeterminado em empresas privadas. A amostra final continha 7.204.643 observações no ano de 2003, $11.405 .309 \mathrm{em}$ 2013 e 8.722 .812 em 2018.

Após a filtragem de dados cada um dos vínculos empregatícios foi classificado em categorias de tarefas a depender da ocupação da CBO2002. Para verificar com mais precisão os efeitos das tecnologias digitais na Indústria de Transformação, a classificação mais adequada é a proposta por Acemoglu e Autor (2011), criada com base nas competências exigidas para a execução de cada tarefa. Sulzbach (2020), em seu segundo ensaio, argumenta que a tipologia de Acemoglu e Autor (2011) não se enquadra para a CBO, pois a classificação brasileira é mais focada nas especificidades das funções ocupacionais em detrimento das competências exigidas para a execução de uma determinada tarefa. No entanto, assim como a CBO, a ISCO88 também não é perfeitamente correspondente ao SOC e à tipologia de Acemoglu e Autor (2011). Diante dessa problemática, Fonseca, Lima e Pereira (2018) propõem um método para refinar a correspondência entre os códigos SOC e a ISCO88 à luz dessa tipologia.

Fonseca, Lima e Pereira (2018) selecionam os descritores $\mathrm{O} *$ NET adotando escalas de importância entre 1 e 5, aplicando componentes principais nos descritores para reduzir suas dimensões e encontrar o conteúdo da tarefa, alocando cada ocupação da ISCO88 em sua tarefa predominante, usando a base de dados de Quadros de Pessoal de Portugal. Os componentes principais são padronizados para terem um média 0 e desvio padrão 1 para cada medida de tarefa. Os autores associam cada ocupação à tarefa com maior nível de intensidade, examinando as ocupações nas categorias mais refinadas para melhorar a correspondência entre os códigos, uma vez que o $\mathrm{O} *$ NET é baseado no código SOC e certas categorias ISCO não oferecem uma correspondência perfeita para o SOC. Assim, os autores conseguem obter uma agregação exata das medidas para a maioria das ocupações. As ocupações que não têm uma agregação exata apresentam descrições correspondentes a mais de uma medida, podendo assumir três categorias [rotineira cognitiva, rotineira manual e não rotineira manual] ${ }^{5}$ ). Ou seja, a classificação de Fonseca, Lima e Pereira (2018) consegue extrair as competências exigidas pelas ocupações da ISCO88, com correspondência exata da maioria das ocupações com os códigos SOC.

Como foi dito na seção anterior, a CBO2002 possui comparabilidade com a ISCO88, então foi possível adotar a classificação de Fonseca, Lima e Pereira (2018) para definir as ocupações da CBO2002 em tarefa rotineira (cognitiva ou manual), manual ou abstrata, enquadrando a classificação brasileira à tipologia de Acemoglu e Autor (2011). A CBO2002 possui uma distribuição mais detalhada das ocupações do que a ISCO88, contendo 49 subgrupos. Com isso, as ocupações ao nível mais desagregado de cinco dígitos não seguem uma distribuição em subgrupos idêntica à da ISCO88. Assim, não é possível fazer a classificação das ocupações ao nível de dois dígitos, sendo usado o nível de desagregação de cinco dígitos.

Cabe ressaltar que a maioria da literatura combina em uma única categoria todos os trabalhos de rotina (tarefas rotineiras cognitivas, tarefas rotineiras manuais e tarefas que podem assumir três categorias). No entanto, em alguns países é importante a separação dessas subcategorias, pois tais tarefas assumem importâncias diferentes, principalmente as tarefas rotineiras cognitivas nos setores de serviços e manufatura, como é o caso de Portugal, segundo Fonseca, Lima e Pereira (2018). No caso da indústria de transformação brasileira, as tarefas rotineiras cognitivas não possuem grande representatividade em nenhuma dos anos analisados neste estudo. Desse modo, para facilitar a análise, segue-se a maioria da literatura, unindo-se as subcategorias de tarefas rotineiras e, também, as ocupações que podem assumir três tipos de tarefas.

\subsection{Modelo Logit Multinomial}

Além do cálculo do RTI para os subgrupos ocupacionais da indústria de transformação, buscou-se investigar os fatores que influenciam a probabilidade de o trabalhador executar uma tarefa abstrata, manual não rotineira ou rotineira. Para tanto, foi adotado o modelo logit multinomial, uma vez que a variável a ser modelada (o tipo de tarefa) é qualitativa, não ordenada e apresenta mais de dois resultados

\footnotetext{
${ }^{5}$ De acordo com Fonseca, Lima e Pereira (2018), o subgrupo 52 de ocupações da ISCO88 (Modelos, vendedores e demonstradores) pode apresentar três tipos de tarefas (rotineira cognitiva, rotineira manual e manual). Esse grupamento guarda correspondência com 11 ocupações da CBO2002.
} 
possíveis.

Formalmente, seja a variável aleatória $y$, assumindo os valores $\{0,1, \ldots, J\}$ para $J$ inteiro positivo, e $\boldsymbol{x}$ um conjunto de variáveis condicionantes. O objetivo do modelo é identificar, ceteris paribus, como as mudanças nos elementos de $\boldsymbol{x}$ afetam as probabilidades de resposta, $P\left(y_{i}=j \mid \boldsymbol{x}_{i}\right), j=0,1,2 \ldots, J$. O logit multinomial possui $J$ categorias de resposta, mais uma categoria de referência. Assim, existem $J$ vetores $\boldsymbol{\beta}$ de parâmetros associados a $\boldsymbol{x}$ a serem estimados. Segundo Wooldridge (2010), o modelo é dado pela seguinte expressão:

$$
P\left(y_{i}=j \mid \boldsymbol{x}_{i}\right)=G\left(\boldsymbol{x}_{i} \boldsymbol{\beta}_{j}\right)
$$

em que $G$ denota a função de distribuição acumulada de uma variável aleatória logística padrão. modelo.

No Quadro 1 apresentam-se as variáveis (dependente e explanatórias) usadas na estimação do

Quadro 1 - Variáveis empregadas no modelo logit multinomial.

\begin{tabular}{|c|c|c|}
\hline Nome da Variável & Descrição & Tipo de variável \\
\hline \multicolumn{3}{|c|}{ Variável dependente } \\
\hline tipotarefa & Tipo de tarefa & $\begin{array}{c}\text { Variável categórica que assume } \\
\text { três possibilidades: rotineira }=1 \text {, } \\
\text { manual }=2 \text {, abstrata }=3\end{array}$ \\
\hline \multicolumn{3}{|c|}{ Variáveis explanatórias } \\
\hline \multicolumn{3}{|c|}{ Dummy de sexo } \\
\hline mulher & Trabalhador do sexo feminino & Binária \\
\hline \multicolumn{3}{|c|}{ Dummies de escolaridade } \\
\hline analf_fund_incom & $\begin{array}{l}\text { Trabalhador analfabeto ou com ensino } \\
\text { fundamental incompleto. }\end{array}$ & Binária \\
\hline fundamental & $\begin{array}{l}\text { Trabalhador com ensino fundamental } \\
\text { completo ou ensino médio incompleto. }\end{array}$ & Binária \\
\hline superior & $\begin{array}{l}\text { Trabalhador com ensino superior ou pós- } \\
\text { graduados (mestrado e doutorado). }\end{array}$ & Binária \\
\hline $\begin{array}{l}\text { Variável omitida: } \\
\text { medio }\end{array}$ & Trabalhador com ensino médio completo. & \\
\hline \multicolumn{3}{|c|}{ Dummies para tamanho da empresa } \\
\hline p_emp & $\begin{array}{c}\text { Trabalhador em estabelecimento com } 20 \text { a } 99 \\
\text { trabalhadores. }\end{array}$ & Binária \\
\hline m_emp & $\begin{array}{l}\text { Trabalhador em estabelecimento com } 100 \text { a } \\
499 \text { trabalhadores. }\end{array}$ & Binária \\
\hline g_emp & $\begin{array}{l}\text { Trabalhador em estabelecimento com } 500 \mathrm{ou} \\
\text { mais trabalhadores. }\end{array}$ & Binária \\
\hline $\begin{array}{l}\text { Variável omitida: } \\
\text { micro_emp }\end{array}$ & $\begin{array}{c}\text { Trabalhador em estabelecimento com até } 19 \\
\text { trabalhadores. }\end{array}$ & \\
\hline \multicolumn{3}{|c|}{ Dummies para região } \\
\hline centro_oeste & $\begin{array}{c}\text { Trabalhador em estabelecimentos localizados } \\
\text { na região Centro-Oeste. }\end{array}$ & Binária \\
\hline norte & $\begin{array}{l}\text { Trabalhadores em estabelecimentos } \\
\text { localizados na região Norte. }\end{array}$ & Binária \\
\hline sudeste & $\begin{array}{c}\text { Trabalhadores em estabelecimentos da região } \\
\text { Sudeste. }\end{array}$ & Binária \\
\hline sul & $\begin{array}{l}\text { Trabalhadores em estabelecimentos da região } \\
\text { Sul. }\end{array}$ & Binária \\
\hline $\begin{array}{l}\text { Variável omitida: } \\
\text { nordeste }\end{array}$ & $\begin{array}{c}\text { Trabalhadores em estabelecimentos do } \\
\text { Nordeste. }\end{array}$ & \\
\hline \multicolumn{3}{|c|}{ Tempo no emprego } \\
\hline tempoemprego & $\begin{array}{l}\text { O tempo de emprego do trabalhador no } \\
\text { estabelecimento, medido em anos. }\end{array}$ & Contínua (anos) \\
\hline \multicolumn{3}{|c|}{ Experiência profissional } \\
\hline$i d 1$ & $\begin{array}{c}\text { A idade declarada pelo trabalhador, adotada } \\
\text { como proxy de sua experiência no mercado de } \\
\text { trabalho, medida em dezenas de anos, para } \\
\text { evitar que os coeficientes estimados sejam } \\
\text { muito pequenos. }\end{array}$ & Contínua (dezenas de anos) \\
\hline$i d 2$ & O quadrado da idade do trabalhador. & $\begin{array}{c}\text { Contínua (dezenas de anos ao } \\
\text { quadrado) }\end{array}$ \\
\hline
\end{tabular}

Fonte: Elaboração própria. 


\section{Resultados}

\subsection{Análise descritiva dos dados}

Após realizar-se a categorização das ocupações em tarefas, foi possível identificar que em todos os anos analisados a maioria dos trabalhadores realizavam tarefas rotineiras, 55,90\% ${ }^{6}, 50,58 \%^{7}$ e $49,69 \%{ }^{8} \mathrm{em}$ 2003, 2013 e 2018, respectivamente. Em segundo estão os trabalhadores que desempenhavam tarefas não rotineiras manuais, representando 34,28\% em 2003, 38,21\% em 2013 e 37,47\% em 2018. Nota-se que em 2013 as tarefas não rotineiras manuais tinham uma participação ligeiramente maior que em 2018, podendo ser um reflexo da crise econômica do país. Já as tarefas abstratas eram realizadas por 9,82\% dos trabalhadores em 2003, 11,21\% em 2013 e 12,84\% em 2018. Percebe-se, assim, que as tarefas não rotineiras manuais e abstratas vêm aumentando sua participação na indústria de transformação entre o período de 2003 e 2018. Em contrapartida, as tarefas rotineiras, apesar de serem executadas pela maioria dos trabalhadores, vêm diminuindo sua participação ao longo dos anos, como mostra a Tabela 1, a seguir. Esses resultados eram esperados, uma vez que vão de encontro com os resultados obtidos pelas pesquisas citadas na seção 2.2.

Tabela 1 - Distribuição (em \%) dos vínculos empregatícios na indústria de transformação segundo tipo de tarefa desempenhada. Brasil, 2003-2013-2018.

\begin{tabular}{lrrrc}
\hline Ano & Abstrata & Manual & Rotineira & Total \\
\hline $\mathbf{2 0 0 3}$ & 9,82 & 34,28 & 55,90 & 100,00 \\
\hline $\mathbf{2 0 1 3}$ & 11,21 & 38,21 & 50,58 & 100,00 \\
\hline $\mathbf{2 0 1 8}$ & 12,84 & 37,47 & 49,69 & 100,00
\end{tabular}

Fonte: Elaboração própria com base nos microdados da RAIS 2003, 2013 e 2018.

Como foi citado na seção 2.1, as tarefas rotineiras são frequentemente realizadas por trabalhadores de baixa e média qualificação, as não rotineiras manuais por trabalhadores com qualificação intermediária e as abstratas por indivíduos com alta qualificação. A Tabela 2, a seguir, mostra que até 2013 a maioria dos trabalhadores que executavam tarefas abstratas possuíam o ensino médio: 38,64\% em 2003 e 48,39\% em 2013. A partir de 2018 essa situação se inverteu, com os trabalhadores com diploma universitário tornando-se a maioria daqueles que realizavam esse tipo de tarefa $(47,41 \%)$. Quanto às tarefas não rotineiras manuais e rotineiras, os percentuais de trabalhadores com ensino superior são baixos, mas se verificou um salto de $0,82 \%$ e 2,96\%, respectivamente, em 2003, para 2,42\% e 7,39\%, em 2018. Em 2003, a maioria dos trabalhadores que executavam tarefas não rotineiras manuais e rotineiras era analfabeta ou tinha fundamental incompleto, representando $44,91 \%$ e $34,60 \%$ dos trabalhadores, respectivamente. Já em 2013 a maior parcela dos trabalhadores dessas tarefas possuía ensino médio completo ( $48,02 \%$ e $53 \%$, respectivamente).

Tabela 2 - Distribuição (em \%) dos vínculos empregatícios na indústria de transformação segundo grau de escolaridade, por tipo de tarefa. Brasil, 2003, 2013 e 2018.

\begin{tabular}{|c|c|c|c|c|c|c|c|c|c|}
\hline \multirow{3}{*}{ Escolaridade } & \multicolumn{9}{|c|}{ Tarefa } \\
\hline & \multicolumn{3}{|c|}{ Abstrata } & \multicolumn{3}{|c|}{ Manual } & \multicolumn{3}{|c|}{ Rotineira } \\
\hline & 2003 & 2013 & 2018 & 2003 & 2013 & 2018 & 2003 & 2013 & 2018 \\
\hline $\begin{array}{l}\text { Analfabetos ou } \\
\text { fund. Incompleto }\end{array}$ & 10,69 & 3,41 & 1,98 & 44,91 & 24,16 & 18,90 & 34,60 & 16,51 & 12,57 \\
\hline $\begin{array}{l}\text { Fundamental } \\
\text { completo }\end{array}$ & 17,37 & 8,81 & 5,70 & 32,08 & 26,75 & 21,95 & 33,88 & 25,62 & 20,34 \\
\hline Médio completo & 38,64 & 48,39 & 44,91 & 22,18 & 48,02 & 56,72 & 28,56 & 53,00 & 59,70 \\
\hline Superior completo & 33,30 & 39,38 & 47,41 & 0,82 & 1,07 & 2,42 & 2,96 & 4,87 & 7,39 \\
\hline Total & 100,00 & 100,00 & 100,00 & 100,00 & 100,00 & 100,00 & 100,00 & 100,00 & 100,00 \\
\hline
\end{tabular}

Fonte: Elaboração própria com base nos microdados da RAIS 2003, 2013 e 2018.

\footnotetext{
${ }^{6}$ Em 2003, 11,12\% dos vínculos empregatícios da indústria de transformação estavam associados a tarefas rotineiras cognitivas, $42,11 \%$ a tarefas rotineiras manuais e $2,55 \%$ a tarefas que podiam assumir três categorias (rotineira cognitiva, rotineira manual e não rotineira manual).

${ }^{7} \mathrm{Em} 2013$, 11,08\% dos trabalhadores executavam tarefas rotineiras cognitivas, $37,19 \%$ tarefas rotineiras manuais e $2,31 \%$ tarefas que assumiam três categorias.

${ }^{8}$ No ano de 2018 as tarefas rotineiras cognitivas representavam 11,54\% dos vínculos, tarefas rotineiras manuais $35,51 \%$ e tarefas que assumiam três categorias $2,62 \%$.
} 
O analfabetismo e a evasão escolar sempre foram questões problemáticas no Brasil, e estão ligadas à falta de escolas, de material escrito, à pobreza, à desigualdade, à marginalização em relação ao mercado, entre outros fatores. A erradicação do analfabetismo e as condições de permanência dos estudantes nas escolas foram pauta de várias campanhas do Governo Federal. Em 2001, com a criação do Plano Nacional de Educação, os índices começaram a ter uma queda mais acentuada. Em 2003, 1,49\% dos trabalhadores da indústria de transformação eram analfabetos, percentual menor em relação ao observado nos anos 1990. A evasão escolar, porém, ainda era bastante elevada em 2003, com 34,29\% dos trabalhadores da indústria de transformação não tendo concluído o ensino fundamental. Nos últimos anos os indicadores educacionais avançaram muito, porém ainda falta muito em comparação com outros países em estágio equivalente de desenvolvimento. Por exemplo, segundo os dados da Organização para a Cooperação e Desenvolvimento Econômico (OCDE) ${ }^{9}$, na Argentina e no Chile 21,41\% e 25,17\% da população, respectivamente, possuía ensino superior completo em 2017. Já no Brasil, em 2018, apenas $16,5 \%$ da população brasileira possuía ensino superior e 47,4\% havia concluído o ensino médio, de acordo com a Pesquisa Nacional por Amostra de Domicílios Contínua (PNAD Contínua/IBGE). Esses índices educacionais do Brasil refletem-se nos resultados apresentados na Tabela 2, em que apesar da capacidade da força de trabalho ser limitada em diversas áreas do conhecimento, é notório que em 2018 a diferença dos níveis educacionais nessas tarefas é menor em relação aos níveis dos anos de 2003 e 2013.

Na Tabela 2, além de ser possível identificar uma melhora nos indicadores educacionais, outros dois pontos chamam atenção. O primeiro é que, em todos os anos, os trabalhadores de tarefas rotineiras apresentavam escolaridade ligeiramente maior que os de atividades não rotineiras manuais, resultado diferente do previsto na teoria de Autor, Levy e Murnane (2003). Isso provavelmente ocorre devido à qualificação dessa tarefa ser mais especificamente ligada à aprendizagem e ao treinamento para o trabalho. O segundo ponto trata da maior proporção de trabalhadores com ensino médio na execução de todas as tarefas. Um dos motivos para esse resultado pode ser devido à expansão do ensino médio técnico ocorrida nos anos 2000. O Decreto $\mathrm{n}^{\mathrm{o}} 5.154 / 2004^{10}$, de julho de 2004, permitiu que o ensino médio fosse integrado ao técnico e com a educação de jovens e adultos incorporado à qualificação e a formação profissional, denominada essa modalidade de ensino técnico de nível médio. Anos depois, esse decreto foi transformado na Lei $\mathrm{n}^{\mathrm{o}} 11.741 / 2008^{11}$, de julho de 2008, também conhecida como "lei educação profissional e tecnológica", instituindo que a educação de jovens e adultos precisava ser vinculada, preferencialmente, à educação profissional. Com isso, ainda em 2008, foi necessário ampliar essa Lei, com a Lei n. $11.892^{12}$ de dezembro de 2008, para instituir a Rede de Educação Profissional, Científica e Tecnológica, composta pelos Institutos Federais de Educação, Ciência e Tecnologia, a Universidade Tecnológica Federal do Paraná, os Centros Federais de Educação Tecnológica Celso Suckow da Fonseca do Rio de Janeiro e Minas Gerais (CEFET-RJ e CEFET-MG) e as escolas técnicas vinculadas às universidades federais. De acordo com os dados do Censo da Educação Básica (INEP/MEC ${ }^{13}$ ), em 2003 havia 2.789 estabelecimentos da educação profissional regular e 589.383 pessoas matriculadas. Já em 2018, após as Leis de expansão, o número de estabelecimentos era 6.769 e eram 1.903 .230 os matriculados. A ampliação da proporção de trabalhadores com ensino técnico no Brasil provavelmente refletiu-se no setor da indústria de transformação, em que trabalhadores com formação técnica podem desenvolver atividades abstratas.

Cumpre notar, ainda, que a expansão do ensino médio pode ter convertido esse nível educacional em um sinalizador no mercado de trabalho, independentemente do tamanho da empresa e do conteúdo da ocupação. Spense (1973) foi um dos precursores da teoria da sinalização ${ }^{14}$, desenvolvendo o modelo

\footnotetext{
${ }^{9}$ Para mais informação acesse: <https://doi.org/10.1787/36bce3fe-en>

${ }^{10}$ Regulamenta a educação profissional, prevista no art. 39 da Lei n ${ }^{\circ}$ 9.394, de 20 de dezembro de 1996 (Lei de Diretrizes e Bases da Educação Nacional), contidas nas diretrizes curriculares nacionais. Para mais informação acesse: < http://www.planalto.gov.br/ccivil_03/_ato2004-2006/2004/decreto/d5154.htm>

${ }^{11}$ Lei $n^{\circ}$. 11.741/2008 alterou a Lei de Diretrizes e Bases da Educação Nacional nº. 9.394/199666, para redimensionar, institucionalizar e integrar as ações da educação profissional técnica de nível médio, da educação de jovens e adultos e da educação profissional e tecnológica. Para mais informação acesse: <http://www.planalto.gov.br/ccivil_03/_ato2007-2010/2008/lei/111741.htm>

12 Inaugura a Rede Federal de Educação Profissional, Científica e Tecnológica e cria os Institutos Federais de Educação, Ciência e Tecnologia, e dá outras providências. Para mais informação acesse: <http://www.planalto.gov.br/ccivil_03/_ato2007-2010/2008/lei/111892.htm>

${ }^{13}$ Para mais informação acesse: <http://inep.gov.br/web/guest/sinopses-estatisticas>

${ }^{14}$ Spense (1973) explica que na maioria dos mercados de trabalho o empregador não tem certeza das capacidades produtivas de um indivíduo no momento em que o contrata. Assim, por essas capacidades não serem conhecidas, num primeiro momento a decisão é incerta. A teoria da sinalização busca analisar situações em que partes de um
} 
de equilíbrio de sinalização, em que um equilíbrio pode ser pensado como um conjunto de crenças do empregador que geram tabelas salariais ofertadas, decisões de sinalização de candidatos, contratações e novos dados de mercado sobre tempo que são consistentes com as crenças iniciais. $\mathrm{O}$ autor considera como um dos sinais a educação, desenvolvendo o modelo de sinalização educacional ${ }^{15}$. Diante disso, o ensino médio no Brasil pode ter se tornado um sinal, crescendo a homogeneidade dos trabalhadores no que se refere ao nível educacional. Ou seja, a qualificação mínima para se trabalhar passa a ser o ensino médio, que não reflete necessariamente a produtividade ou o conteúdo da tarefa a ser desempenhada.

Outro fator que pode explicar a grande participação dos trabalhadores com ensino médio em todas as tarefas é o fenômeno da sobreeducação - que acontece quando a oferta de trabalhadores com nível educacional mais elevado não está perfeitamente ajustada à demanda. Segundo Reis (2012), à luz da Teoria de Mismatch, a sobreeducação está associada com informação imperfeita e com os custos da procura por emprego, resultando em uma combinação inadequada e sub ótima. Ou seja, não há um matching entre as qualificações demandadas pelas empresas e as oferecidas pelos trabalhadores, causando desequilíbrio no mercado de trabalho.

Apesar da distribuição das habilidades em cada tarefa apresentar comportamento um pouco diferente do estabelecido na hipótese de Autor, Levy e Murnane (2003), ainda assim os resultados confirmam a hipótese das qualificações características de cada tarefa.

A Teoria do Capital Humano busca explicar as diferenças de ganhos de produtividade gerados pelo fator trabalho na produção. Segundo essa teoria, trabalhadores com alto nível de qualificação recebem salários maiores em relação aos não qualificados. Partindo dessa premissa, no modelo de Autor e Dorn (2013) os trabalhadores que realizam tarefas abstratas possuem salários maiores em comparação aos que realizam tarefas não rotineiras manuais, que, por sua vez, recebem mais do que os que desempenham tarefas rotineiras. Santos, Vaz e Oliveira (2019), citados na seção 2.2, encontram esses resultados para o Brasil, em que o prêmio salarial dos trabalhadores que desempenham ocupações de natureza não manual e não rotineira é maior. Por meio da Tabela 3 percebe-se que os resultados corroboram, como esperado, as premissas de Autor e Dorn (2013).

Tabela 3 - Distribuição (em \%) dos vínculos empregatícios na indústria de transformação segundo faixas de remuneração média anual (em salários mínimos), por tipo de tarefa. Brasil, 2003, 2013 e 2018.

\begin{tabular}{crrrrrrrrrr}
\hline \multirow{2}{*}{$\begin{array}{c}\text { Faixas de } \\
\text { Remuneração }\end{array}$} & \multicolumn{3}{c}{ Abstrata } & \multicolumn{3}{c}{ Tarefa } \\
\cline { 2 - 11 } & 2003 & 2013 & 2018 & 2003 & 2013 & 2018 & 2003 & 2013 & 2018 \\
\hline $\mathbf{0 , 5}$ a 1 SM & 0,83 & 1,10 & 0,84 & 4,39 & 4,95 & 3,50 & 3,22 & 5,42 & 3,67 \\
\hline $\mathbf{1 , 0 1}$ a 2 SM & 14,46 & 19,72 & 19,53 & 38,40 & 54,90 & 57,58 & 47,66 & 60,74 & 61,38 \\
\hline $\mathbf{2 , 0 1}$ a 5 SM & 28,62 & 37,08 & 41,11 & 42,17 & 34,38 & 34,42 & 36,21 & 27,45 & 29,24 \\
\hline $\mathbf{5 , 0 1}$ a 10 SM & 23,57 & 22,63 & 22,55 & 11,38 & 4,85 & 3,90 & 8,78 & 4,70 & 4,41 \\
\hline$\geq \mathbf{1 0 , 0 1}$ SM & 32,52 & 19,46 & 15,97 & 3,66 & 0,91 & 0,60 & 4,14 & 1,68 & 1,31 \\
\hline Total & 100,00 & 100,00 & 100,00 & 100,00 & 100,00 & 100,00 & 100,00 & 100,00 & 100,00 \\
\hline
\end{tabular}

Fonte: Elaboração própria com base nos microdados da RAIS 2003, 2013 e 2018.

Para uma comparação salarial entre os anos é necessário que os valores sejam deflacionados. O valor nominal do salário mínimo foi deflacionado utilizando o Índice Nacional de Preço ao Consumidor (INPC) e adotando-se 2018 como base. Através dos resultados verifica-se que embora em 2013 e 2018 a proporção dos trabalhadores nas faixas salariais mais altas tenha diminuído em relação a 2003, os salários reais nesses anos são consideravelmente maiores que em 2003. Isso é resultado da política de valorização do salário mínimo, contribuindo para a redução da desigualdade de renda e salarial.

contrato sinalizam algumas habilidades ou características antes de firmado o contrato. O sinal é uma atividade crível que prova que um determinado indivíduo tem as habilidades ou característica necessárias.

${ }^{15}$ Nesse modelo a educação é medida por uma quantidade escalar, dividida em dois grupos de pessoas: algumas adequadas para certos tipos de trabalho e outras adequadas para outros tipos. Dada a escala salarial ofertada, os membros de cada grupo selecionam os níveis ótimos de educação. Assim, os indivíduos buscam maximizar sua função utilidade escolhendo o nível ótimo de educação, em que qualquer outro nível educacional implicaria custos adicionais de sinalização sem um correspondente aumento salarial. 


\subsection{Análise do RTI}

Como foi dito na seção 3.1, para o cálculo do RTI foram considerados grandes grupos ocupacionais, a exemplo de Fonseca, Lima e Pereira (2018) e Silva (2018). Os oito grandes grupos da CBO são: Diretores e executivos, Profissionais e Técnicos, Atividade Administrativa, Serviços Pessoais, Agricultura, Indústria/ Construção e Artífices, Operadores de Instalação de Máquinas e Trabalhadores de Montagem e Trabalhadores Manuais Qualificados.

Para um melhor entendimento da operação de cálculo da medida de intensidade da tarefa de rotina, a Tabela 4 apresenta um resumo esquemático dos componentes constituintes do RTI nos anos de 2003, 2013 e 2018, segundo grupo ocupacional. A tabela também indica se o valor médio da tarefa no grupo de ocupação é maior (+) ou menor (-) que a média da tarefa em todas as ocupações. Os campos sombreados indicam o maior valor da tarefa para cada grupo de ocupação.

Tabela 4 - Intensidade de tarefas dos principais grupos de ocupação na indústria de transformação.

Brasil, 2003, 2013 e 2018.

\begin{tabular}{|c|c|c|c|c|c|c|c|c|c|c|c|c|}
\hline \multirow{2}{*}{$\begin{array}{c}\text { Grandes } \\
\text { Grupos } \\
\text { Ocupacionais }\end{array}$} & \multicolumn{3}{|c|}{ Tarefas Rotineiras } & \multicolumn{3}{|c|}{$\begin{array}{c}\text { Tarefas não } \\
\text { rotineiras Manual }\end{array}$} & \multicolumn{3}{|c|}{ Tarefas Abstratas } & \multicolumn{3}{|c|}{ RTI } \\
\hline & 2003 & 2013 & 2018 & 2003 & 2013 & 2018 & 2003 & 2013 & 2018 & 2003 & 2013 & 2018 \\
\hline $\begin{array}{l}\text { Diretores e } \\
\text { executivos }\end{array}$ & - & - & - & - & - & - & + & + & + & $-11,83$ & $-12,27$ & $-12,10$ \\
\hline $\begin{array}{l}\text { Profissionais e } \\
\text { Técnicos }\end{array}$ & + & + & + & - & - & - & + & + & + & $-1,48$ & $-1,73$ & $-1,78$ \\
\hline $\begin{array}{l}\text { Atividade } \\
\text { Administrativa }\end{array}$ & + & + & + & - & - & - & - & - & - & 13,40 & 13,89 & 13,65 \\
\hline $\begin{array}{l}\text { Serviços } \\
\text { Pessoais }\end{array}$ & + & + & + & + & + & + & - & - & - & 0,53 & 0,53 & 0,51 \\
\hline Agricultura & - & - & - & + & + & + & - & - & - & $-12,83$ & $-12,82$ & $-12,31$ \\
\hline $\begin{array}{l}\text { Indústria/ } \\
\text { Construção e } \\
\text { Artífices }\end{array}$ & + & + & + & + & + & + & - & - & - & 0,23 & $-0,05$ & $-0,17$ \\
\hline $\begin{array}{l}\text { Operadores de } \\
\text { Instalação e } \\
\text { Máquinas e } \\
\text { Trabalhadores } \\
\text { de Montagem }\end{array}$ & + & + & + & + & + & + & - & - & - & 2,17 & 1,75 & 1,62 \\
\hline $\begin{array}{l}\text { Trabalhadores } \\
\text { Manuais } \\
\text { Qualificados }\end{array}$ & - & - & - & + & + & + & - & - & - & $-13,68$ & $-14,40$ & $-14,15$ \\
\hline & & & & RTI m & & & & & & $-12,89$ & $-13,78$ & $-13,65$ \\
\hline
\end{tabular}

Fonte: Elaboração própria com base nos microdados da RAIS 2003, 2013 e 2018.

Nota: A tabela indica se o valor médio da tarefa no grupo de ocupação é maior (+) ou menor (-) que a média da tarefa em todas as ocupações. Os campos sombreados indicam o maior valor da tarefa para cada grupo de ocupação.

Percebe-se que em 2003 quatro grandes grupos ocupacionais apresentavam valores negativos de RTI, enquanto em 2013 e 2018 o número de grandes grupos com valores negativos de RTI aumentou para cinco. Valores negativos de RTI indicam que as ocupações desses grupos são majoritariamente pertencentes a tarefas manuais não rotineiras e/ou abstratas. Nos grupos Diretores e executivos e Profissionais e Técnicos predominam, em todos os anos estudados, as tarefas abstratas, com RTI de 11,83 e -1,48, respectivamente, em 2003, -12,27 e -1,73 em 2013, e -12,10 e -1,78 em 2018. Nos grupos Agricultura e Trabalhadores Manuais Qualificados são as tarefas não rotineiras manuais a maioria, com RTI de $-12,83$ e $-13,68$ em 2003, -12,82 e -14,40 em 2013, e -12,31 e -14,15 em 2018. No grupo Indústria/Construção e Artífices, nota-se que em 2003 a maioria dos trabalhadores desempenhavam tarefas rotineiras, tendo assim um RTI positivo de 0,23 . Esse cenário, contudo, vem se modificando ao longo dos anos, já que em 2013 e 2018 a maioria dos trabalhadores passaram a executar tarefas não rotineiras manuais, apresentando um RTI negativo de $-0,05$ e - 0,17 , respectivamente. Quanto aos grupos Atividade Administrativa, Serviços Pessoais, e Operadores de Instalação e Máquinas e Trabalhadores de Montagem, os empregos são majoritariamente pertencentes às tarefas rotineiras, apresentando resultados positivos de RTI de 13,40, 0,53 e 2,17, respectivamente, em 2003; 13,89, 0,53 e 1,75 em 2013; e 13,65, 0,51 e 1,62 em 2018. 
Através desses resultados nota-se que no decorrer dos anos os valores de RTI diminuíram ainda mais nos grupos ocupacionais: Profissionais e Técnicos; Serviços Pessoais; Indústria/ Construção e Artífices; e Operadores de Instalação e Máquinas e Trabalhadores de Montagem. Nos grupos ocupacionais Diretores e Executivos e Trabalhadores Manuais Qualificados, os valores de RTI se tornaram mais negativos entre 2003 e 2013, porém em 2018 há um pequeno aumento em relação a 2013. Já no grupo Agricultura ocorreram aumentos nos valores negativos de RTI de 2003 para 2018. Quanto ao grupo de Atividades Administrativas, de 2003 para 2013 aumentou seu valor positivo de RTI, e em 2018 ocorreu uma queda em relação a 2013, porém ainda assim o valor é maior em comparação a 2003. Desta forma identifica-se que na maioria dos grupos ocupacionais com RTI negativo, o valor de RTI em 2013 era menor que em 2018, denotando nesses grupos redução da intensidade da polarização, o que pode estar associado à crise econômica vivida pelo país e eventual redução de investimento das empresas em máquinas e equipamentos. Dentre os grupos com RTI negativo, somente Profissionais e Técnicos e Operadores de Instalação e Máquinas e Trabalhadores de Montagem apresentaram diminuição dos valores de RTI entre os anos estudados, o que pode ser um indicativo de que esses grupos ocupacionais sofreram menos com os efeitos da crise econômica.

Um índice de intensidade de tarefas rotineiras inferior implica que a hipótese de rotinização se confirma, uma vez que a adoção de inteligência artificial reduz o trabalho de tarefas rotineiras e aumenta a contribuição do trabalho de tarefas não rotineiras manuais nas indústrias, ou seja, indica um deslocamento de trabalhadores intensivos em tarefas de rotinas (baixa qualificação) para tarefas manuais não rotineiras. Na Figura 1 é possível ver mais claramente esse resultado, em todos os anos, em que a intensidade de tarefas rotineiras é mais alta no meio da distribuição de ocupações. Na parte inferior da distribuição, onde ficam as tarefas manuais não rotineiras e abstratas, percebe-se que a cauda é mais densa, sobretudo devido a tarefas manuais, indicando que as caudas inferiores da distribuição de emprego polarizam.

Figura 1 - Densidade do RTI na indústria de transformação. Brasil, 2003, 2013 e 2018.

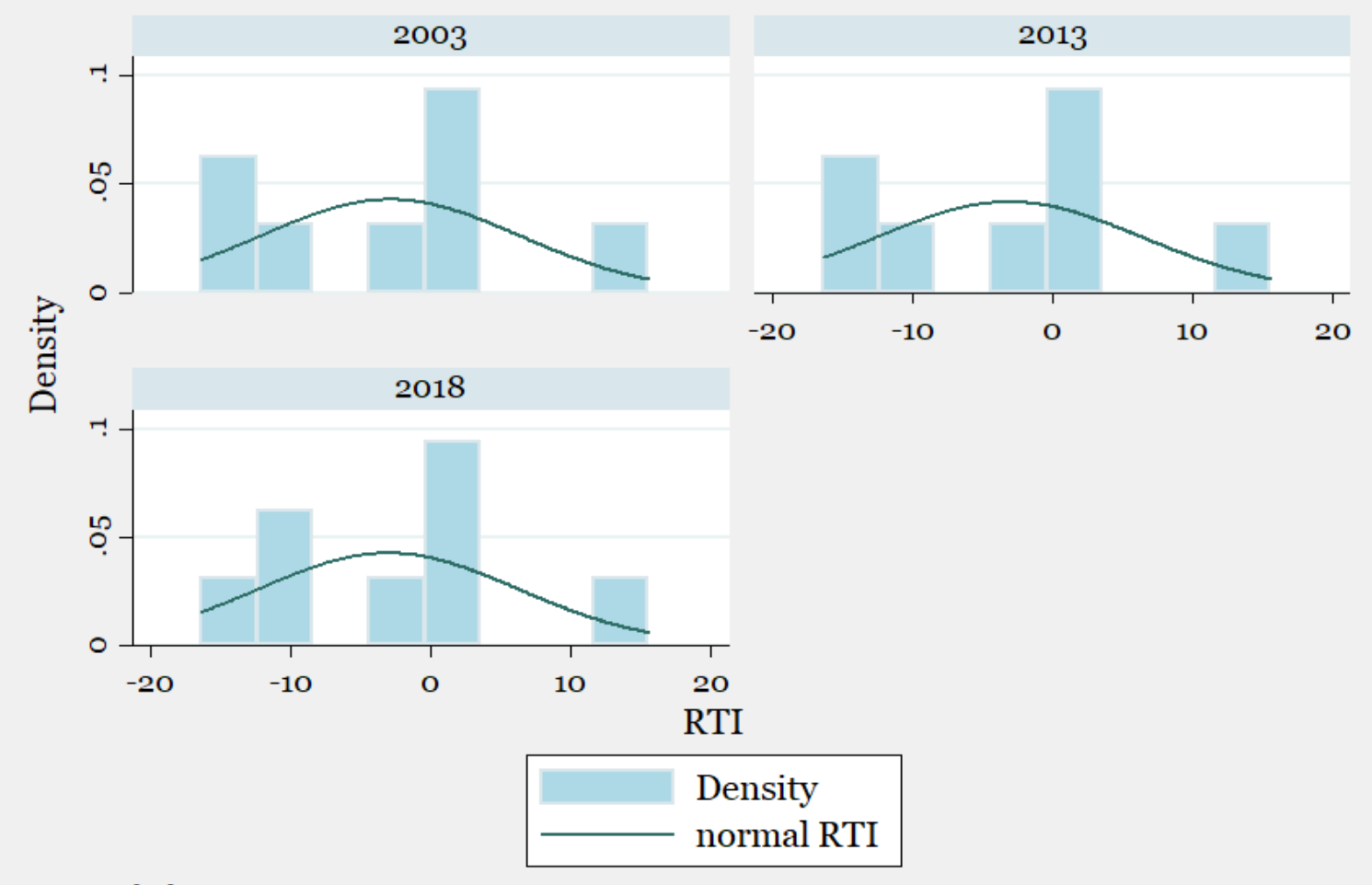

Graphs by Ano

Fonte: Elaboração própria com base nos microdados da RAIS 2003, 2013 e 2018.

Nota-se que a diferença entre os histogramas é praticamente imperceptível, pois de 2003 para 2018 a intensificação da polarização foi baixa, observando-se um RTI médio de -12,89 em 2003, $-13,78$ em 2013 e -13,65 em 2018. Conforme mencionado anteriormente, o Brasil ainda não adotou uma implementação oficial da Indústria 4.0, porém as indústrias o vêm fazendo de forma independente. Através dos resultados percebe-se que as tecnologias características dessa nova forma de produção adotada pelas indústrias ainda não ocasionaram grandes mudanças na estrutura do emprego no Brasil. 
As mudanças observadas estão mais associadas à queda do custo do capital computacional, como a teoria de Autor, Levy e Murnane (2003) citada na seção 2 aponta.

\subsection{Análise do Logit Multinomial}

Na Tabela 5 são apresentados os resultados do modelo logit, estimado conforme proposto na seção 3.3, para o ano de 2018. A coluna Manual traz a estimativa do coeficiente associado a cada variável explanatória do modelo, ao se considerar a probabilidade de o trabalhador executar tarefas não rotineiras manuais, em relação a tarefas rotineiras (categoria de base). Já a coluna Abstrata apresenta os respectivos coeficientes quando se considera a probabilidade de o trabalhador desempenhar uma tarefa abstrata, em relação a tarefas rotineiras.

Tabela 5 - Probabilidades calculadas e medidas de qualidade do ajustamento, indústria de transformação. Brasil, 2018.

\begin{tabular}{|c|c|c|c|c|}
\hline \multirow{2}{*}{ Variáveis } & \multicolumn{2}{|c|}{ Manual } & \multicolumn{2}{|c|}{ Abstrata } \\
\hline & Coeficiente & Desvio padrão & Coeficiente & Desvio Padrão \\
\hline Constante & $-0,5859458 * * *$ & 0,0087201 & $-3,0745930 * * *$ & 0,0152297 \\
\hline mulher & $-1,0260080 * * *$ & 0,0017867 & $-0,3092032 * * *$ & 0,0025415 \\
\hline$i d 1$ & $0,1705641 * * *$ & 0,0046170 & $0,5498921 * * *$ & 0,0079844 \\
\hline$i d 2$ & $-0,0029124 * * *$ & 0,0006018 & $-0,0590178 * * *$ & 0,0010321 \\
\hline analf_fund_incom & $0,3547955 * * *$ & 0,0022392 & $-1,6781610 * * *$ & 0,0071046 \\
\hline fundamental & $0,1357745 * * *$ & 0,0019302 & $-0,9937535^{* * *}$ & 0,0044103 \\
\hline superior & $-1,0834930 * * *$ & 0,0041703 & $2,0332980 * * *$ & 0,0028094 \\
\hline norte & $-0,0443785^{* * *}$ & 0,0046126 & $0,2497051 * * *$ & 0,0073138 \\
\hline sudeste & $0,0615470 * * *$ & 0,0023557 & $0,1885475 * * *$ & 0,0039918 \\
\hline sul & $-0,1108529 * * *$ & 0,0025144 & $0,1028906 * * *$ & 0,0043104 \\
\hline centro_oeste & $0,2145724 * * *$ & 0,0034945 & $0,1900778 * * *$ & 0,0060684 \\
\hline p_emp & $0,0193462 * * *$ & 0,0022003 & $0,0548560 * * *$ & 0,0036851 \\
\hline m_emp & $0,1640897 * * *$ & 0,0022241 & $0,2755328 * * *$ & 0,0035508 \\
\hline g_emp & $0,4035525^{* * *}$ & 0,0021857 & $0,2626501 * * *$ & 0,0035780 \\
\hline tempoemprego & $-0,0457671 * * *$ & 0,0001684 & $0,0247459 * * *$ & 0,0002207 \\
\hline N. Observações & 8.722 .812 & & & \\
\hline Pseudo R2 de McFadden & 0.1234 & & & \\
\hline $\begin{array}{l}\text { Prob. > chi } 2 \\
\text { Significante a }(* * *) 1 \%(* *\end{array}$ & $\begin{array}{c}0.0000 \\
5 \%(*) 10 \%\end{array}$ & & & \\
\hline
\end{tabular}

Fonte: Elaboração própria com base nos microdados da RAIS, 2018.

O resultado do teste chi-quadrado foi estatisticamente significante ( $\mathrm{p}$-valor $=0,00 \%$ ), indicando que os regressores do modelo, em conjunto, têm um efeito significativo na probabilidade modelada. Ou seja, o conjunto de regressores adotado é congruente para explicar as chances de o trabalhador desempenhar tarefas rotineiras, abstratas e/ou manuais não rotineiras. Considerando o modelo ajustado, foi verificado individualmente se as variáveis são estatisticamente significantes, aplicando-se para tanto testes de razão de verossimilhança (likelihood-ratio test) e de Wald. Ao conduzir ambos os testes para cada variável explanatória do modelo, verificou-se que, ao nível de significância de $1 \%$, todas as variáveis são estatisticamente significantes. Cabe ressaltar que o coeficiente de determinação (Pseudo $\mathrm{R}^{2}$ ) aqui apresentado corresponde à fórmula de McFadden. Essa medida não pode ser interpretada como a proporção da variabilidade total da variável dependente explicada pelo modelo (como seria o caso, em modelos lineares estimados por mínimos quadrados). Dessa forma, mais relevantes em modelos não lineares, como o logit multinomial, são as significâncias estatísticas das variáveis explanatórias e seus efeitos marginais (LONG; FREESE, 2014).

Também foi aplicado o teste de Chow para verificar se há quebra estrutural ao se estimar o modelo em separado para homens e mulheres. A hipótese nula desse teste supõe que não há mudança estrutural, sendo possível estimar um mesmo modelo conjuntamente para homens e mulheres. O resultado do teste 
mostrou, ao nível de significância de $1 \%$, que se deve rejeitar $H_{0}$. Assim, há evidências de que o efeito das covariadas na probabilidade de desempenhar tarefas rotineiras, manuais ou abstratas difere para homens e mulheres.

Após os testes de ajustamento do modelo, foram estimados os efeitos marginais associados às variáveis explanatórias do modelo. Assim, é possível quantificar como alterações nas variáveis explanatórias afetam a probabilidade de um trabalhador desempenhar tarefas rotineiras, manuais não rotineiras e/ou abstrata. Na Tabela 6 apresentam-se os efeitos marginais considerando-se as categorias de base das variáveis binárias e os valores médios das variáveis contínuas.

Tabela 6 - Efeitos marginais (em pontos percentuais), indústria de transformação. Brasil, 2018.

\begin{tabular}{|c|c|c|c|}
\hline Variáveis & Rotineira & Manual & Abstrata \\
\hline mulher & $20,2 * * *$ & $-20,4 * * *$ & $0,2 * * *$ \\
\hline$i d 1$ & $-6,1 * * *$ & $1,8 * * *$ & $4,3 * * *$ \\
\hline$i d 2$ & $0,3 * * *$ & $0,1 * * *$ & $-0,4 * * *$ \\
\hline analf_fund_incom & $-4,9 * * *$ & $11,8 * * *$ & $-6,8 * * *$ \\
\hline fundamental & $-0,4 * * *$ & $5,6 * * *$ & $-5,2 * * *$ \\
\hline superior & $-10,9 * * *$ & $-30,0 * * *$ & $41,0 * * *$ \\
\hline norte & $-0,3 * * *$ & $-2,0 * * *$ & $2,3 * * *$ \\
\hline sudeste & $-2,1 * * *$ & $0,8 * * *$ & $1,3 * * *$ \\
\hline sul & $1,8 * * *$ & $-3,0 * * *$ & $1,2 * * *$ \\
\hline centro_oeste & $-5,3 * * *$ & $4,6 * * *$ & $0,7 * * *$ \\
\hline p_emp & $-0,6^{* * *}$ & $0,3^{* * *}$ & $0,4 * * *$ \\
\hline m_emp & $-4,6 * * *$ & $3,0 * * *$ & $1,6 * * *$ \\
\hline g_emp & $-9,5 * * *$ & $9,0 * * *$ & $0,5 * * *$ \\
\hline tempoemprego & $0,8 * * *$ & $-1,2 * * *$ & $0,3 * * *$ \\
\hline
\end{tabular}

Fonte: Elaboração própria com base nos microdados da RAIS, 2018.

Os resultados mostram, para as variáveis contínuas (id1, id2 e tempoemprego), o efeito do acréscimo de uma unidade na probabilidade de o indivíduo desempenhar uma tarefa rotineira, não rotineira manual e abstrata. No caso das variáveis binárias, o efeito apresentado se refere à variação na probabilidade prevista quando a binária em questão passa de 0 para 1 . Como foi dito anteriormente, é muito importante avaliar as significâncias estatísticas desses efeitos. Conforme se vê, todos os efeitos marginais são estatisticamente significantes ao nível de $1 \%$.

Diante dos resultados, identifica-se que, tudo o mais constante, quando o trabalhador é do sexo feminino, as chances de exercer uma tarefa rotineira aumentam em 20,2 p. p. Em contrapartida, ser mulher reduz a probabilidade de exercer tarefas manuais não rotineiras em 20,4 p. p. Esse resultado suscita a hipótese de ocorrência de segregação ocupacional por gênero em tarefas menos valorizadas socialmente e mais mal remuneradas, como é o caso das tarefas rotineiras.

$\mathrm{O}$ efeito marginal associado à idade, adotada como proxy da experiência profissional, indica que um acréscimo de experiência reduz as chances de o trabalhador desempenhar uma tarefa rotineira e aumenta as chances de se executar tarefas não rotineiras manuais e abstratas. Esse efeito, contudo, não é linear. No caso das tarefas abstratas, por exemplo, há um ponto de inflexão a partir do qual o avanço da idade passa a reduzir a probabilidade de se desempenhar esse tipo de tarefa, sugerindo uma possível preferência por parte das empresas por trabalhadores relativamente mais jovens.

Quando as variáveis analf_fund_incom, fundamental e superior passam de 0 para 1, o efeito é negativo nas tarefas rotineiras, isto é, os trabalhadores com essas escolaridades têm suas chances de desempenhar essa tarefa reduzidas em 4,9 p. p., 0,4 p. p. e 10,9 p. p., respectivamente, relativamente aos trabalhadores com ensino médio completo, que são a categoria de base. Contudo, indivíduos que não concluíram o ensino fundamental, ou que possuem apenas esse nível de escolaridade, têm maiores chances de desempenhar tarefas não rotineiras manuais que os trabalhadores com ensino médio $(+11,8$ p. p. e $+5,6$ p. p., respectivamente). Como era de se esperar, trabalhadores com baixa qualificação possuem menor probabilidade de executar tarefas abstratas. Já para os trabalhadores com ensino superior o efeito é positivo, aumentando as chances de exercer essa atividade em 41 p. p., em comparação com um trabalhador que detém apenas o ensino médio. 
Tudo o mais constante, os trabalhadores das regiões Norte, Sudeste e Centro-Oeste têm menores chances de desempenhar tarefas rotineiras, em comparação a um trabalhador do Nordeste: residir nessas regiões reduz tal probabilidade em 0,3 p. p., 2,1 p. p. e 5,3 p. p., respectivamente. Já o efeito da região Sul é positivo $(+1,8$ p. p.). Os trabalhadores situados no Norte e Sul possuem menor probabilidade $(-2,0$ p. p. e $-3,0$ p. p.) de executar tarefas não rotineiras manuais que os residentes no Nordeste. As chances de exercer tarefas manuais aumenta na região Centro-Oeste $(+4,6$ p. p.), bem como na Sudeste $(+0,8$ p. p.). Quanto às tarefas abstratas, nota-se que o efeito é positivo para todas as regiões, indicando que no Nordeste (categoria de base) é menos provável que um trabalhador desempenhe esse tipo de tarefa.

$\mathrm{O}$ efeito em todos os tamanhos das empresas é negativo nas tarefas rotineiras, ou seja, os trabalhadores possuem menores chances de desempenhar essa tarefa quando a empresa é de porte grande $(-9,5$ p. p.), médio ( $-4,6$ p. p.) ou pequeno (-0,6 p. p.), em comparação a microempresas. Em se tratando das tarefas não rotineiras manuais e abstratas, o efeito é positivo para todas as dummies, indicando que nas microempresas (categoria de base) o trabalhador possui menores chances de desempenhar tais tipos de tarefas.

Um aumento de uma unidade, ou seja, um ano, no tempo de emprego na empresa possui um efeito positivo, porém baixo, nas chances de o trabalhador exercer tarefas rotineiras e abstratas, de 0,8 p. p. e 0,3 p. p., respectivamente. Já em se tratando das tarefas não rotineiras manuais, o efeito é negativo $(-1,2$ p. p.), portanto, ter mais tempo de emprego diminui a probabilidade de executar esse tipo de tarefa.

\section{Considerações Finais}

Através dos resultados obtidos nesta pesquisa nota-se que as tecnologias adotadas pelas indústrias de transformação no Brasil substituem os trabalhadores com baixa qualificação na execução de tarefas rotineiras e complementam os trabalhadores altamente qualificados no desempenho de tarefas abstratas. A maioria dos grupos ocupacionais apresentam valores de RTI negativos, ou seja, os vínculos empregatícios são majoritariamente pertencentes a tarefas abstratas e/ou manuais não rotineiras, concentrando-se na parte inferior da distribuição de ocupações.

Esse resultado significa que, a partir do modelo de Autor e Dorn (2013), a demanda por tarefas abstratas e manuais não rotineiras não admite substitutos próximos, porém, as tarefas rotineiras são substituídas por tecnologias usadas na produção. Isso ocasiona o deslocamento dos trabalhadores das atividades rotineiras para as manuais. Esse deslocamento se dá devido ao aumento dos salários dos trabalhadores de baixa qualificação em tarefas manuais em relação ao salário das tarefas rotineiras, aumentando os fluxos de trabalho de baixa qualificação para atender as ocupações na parte inferior da distribuição de habilidades ocupacionais, polarizando as caudas inferiores das distribuições de salários e empregos. Dessa forma, há evidências de que a polarização de empregos no Brasil foi impulsionada pela tecnologia.

Os resultados do logit multinomial reforçam os aspectos da hipotese de rotinização, indicando que as chances de desempenhar tarefas abstratas aumentam quando o trabalhador possui ensino superior, acumula mais experiência profissional e trabalha em empresas de médio porte.

A polarização do emprego na indústria de transformação brasileira se apoia predominantemente na hipótese de rotinização, uma vez que padrões semelhantes de intensidade de polarização do emprego podem ser encontrados para países mais avançados (por exemplo, EUA e Alemanha) antes de 1990. Além disso, não se observa uma diferença substancial no RTI médio entre 2003, 2013 e 2018. Essa diferença pequena entre os anos estudados indica que as tecnologias digitais características da Indústria 4.0 ainda não provocaram grandes mudanças no mercado de trabalho brasileiro.

\section{Technological Change and Polarization of Employment in Brazil}

Abstract: We study the polarization of employment in the Brazilian labor market due to the advances in digital technologies. The methodology adopted is the Routine Task Intensity Index (RTI) proposed by Autor and Dorn (2013). The RTI was applied to the Manufacturing industry, using 2003, 2013, and 2018 Annual List of Social Information (RAIS) microdata. We also investigate the variables that influence the probability of performing routine, manual, or abstract tasks using a multinomial logit model. Results show that most occupational groups, in all years, have negative RTI values, indicating that jobs are polarized. However, there is no substantial change in RTI values between 2003 and 2018. The 
multinomial logit estimates show that the chances of performing abstract tasks increase when the worker has higher education, accumulates more professional experience, and works in medium-sized companies.

Keywords: Technical Progress; Industry 4.0; Labor Market; Job Polarization; Manufacturing Industry.

\section{Referências bibliográficas}

ACEMOGLU, D.; AUTOR D. H. Skills, Tasks and Technologies: Implications for Employment and Earnings. In: ASHENFELTER, O.; CARD, D. Handbook of Labor Economics. 1st Edition, Amsterdam: Elsevier Inc, 2011, v. 4, pp. 1043-1171.

AUTOR, D. H.; LEVY, F.; MURNANE, R. J. The Skill Content of Recent Technological Change: An Empirical Exploration. The Quarterly Journal of Economics, v. 118, n. 4, pp. 1279-1333, 2003.

AUTOR, D. H.; KATZ, L. F.; KEARNEY, M. S. The Polarization of the U.S. Labor Market. American Economic Review, v. 96, n. 2, pp. 189-194, 2006.

AUTOR, D. H.; DORN, D. The Growth of Low-Skill Service Jobs and the Polarization of the US Labor Market. American Economic Review, v. 103, n. 5, pp. 1553-1597, 2013.

AUTOR, D. H. Why Are There Still So Many Jobs? The History and Future of Workplace Automation, Journal of Economic Perspectives, v. 29, n. 3, pp. 3-30, 2015.

AUTOR, D. H.; DORN, D.; HANSON, G. H. The China Shock: Learning From Labor Market Adjustment to Large Changes in Trade. Massachusetts: National Bureau of Economic Research, jan. 2016. (Working Paper 21906).

BRESSAN, G. S.; HERMETO, A. M. Polarização do Mercado de Trabalho Sob Viés Tecnológico e Impactos sobre Diferenciais Salariais por Gênero. In: ANPEC - $\mathbf{3 7}^{\mathbf{0}}$ Encontro Nacional de Economia. Foz do Iguaçu: 2009. Disponível em: http://www.anpec.org.br/encontro2009/inscricao.on/arquivos/00059b976a29e1cbc7e6e948805e540fa0d.pdf. Acesso em: 19 ago. 2020.

CNI. Desafios para Indústria 4.0 no Brasil. Brasília: 2016. Disponível em: file:///C:/Users/Usuario/Downloads/1436-

Desafios_para_a_industria_40_no_Brasil_CNI_2016\%20(2).pdf . Acesso em: 5 mar. 2019.

CONSOLI, D.; SÁNCHEZ-BARRIOLUENGO, M. Polarization and the growth of low-skill service jobs in Spanish local labor markets. Journal of Regional Science, v. 59, n. 1, pp. 145-162, 2018. Disponível em: https://onlinelibrary.wiley.com/doi/abs/10.1111/jors.12409. Acesso em: 31 jul. 2020.

CORSEUIL, C. H. L.; POOLE, J. P.; ALMEIDA, R. K. The Impact of Digital Technologies on Worker Tasks: Do Labor Policies Matter? Brasília: IPEA, set. 2018. (Discussion Paper n. 234). Disponível em:

https://www.ipea.gov.br/portal/index.php?option=com_content\&view=article\&id=34219\&Itemid=433. Acesso em: 14 out. 2020.

FIRPO, S.; FORTIN, N. M.; LEMIEUX, T. Occupational Tasks and Changes in the Wage Structure. Germany: The Institute for the Study of Labor (IZA), 2011. (Discussion Paper n. 5546). Disponível em: http://ftp.iza.org/dp5542.pdf. Acesso em: 15 dez. 2019.

FONSECA, T.; LIMA, F.; PEREIRA, S. C. Job polarization, technological change and routinization: Evidence for Portugal. Labour Economics, v. 51, issue C, pp. 317-339, 2018.

FUNCHAL, B.; SOARES, J. S. Understanding demand for skills after technological trade liberalization. Fucape Business School, out. 2013. (Fucape Working Papers n. 40). Disponível em: http://legado.fucape.br/_public/workingpapers/40-2013.pdf. Acesso em: 12 nov. 2020. 
change and offshoring. American Economic Review, v. 104, n. 8, p. 2509-2526, 2014.

GÓRKA, S.; HARDY, W.; KEISTER, R.; LEWANDOWSKI, P. Tasks and Skills in European Labour Markets. Warsaw: Institute for Structural Research (IBS), may 2017. (IBS Research Report 03/2017). Disponível em: https://ibs.org.pl/app/uploads/2018/03/IBS_Research_Report_03_2017.pdf. Acesso em: 10 out. 2019.

HARDY, W.; LEWANDOWSKI, P.; PARK, A.; YANG, D. The Global Distribution of Routine and Non-Routine Work. Warsaw: Institute for Structural Research (IBS), jun. 2018. (IBS Working Paper 05/2018). Disponível em: http://conference.iza.org/conference_files/WoLabConf_2018/lewandowski_p9882.pdf. Acesso em: 10 out. 2019.

KEISTER, R.; LEWANDOWSKI , P. A routine transition? Causes and consequences of the changing content of jobs in central and eastern Europe. Warsaw: Institute for Structural Research (IBS), jun. 2016. (IBS Policy Paper 05/2016). Disponível em: https://ibs.org.pl/en/publications/a-routinetransition-causes-and-consequences-of-the-changing-content-of-jobs-in-central-and-eastern-europe/.

Acesso em: 10 out. 2019.

LONG, J. S.; FREESE, J. Regression Models for Categorical Dependent Variables Using STATA. Third edition. Texas: Stata Press Publication, 2014.

MAHUTGA, M. C.; CURRAN, M.; ROBERTS, M. Job tasks and the comparative structure of income and employment: Routine task intensity and offshorability for the LIS. International Journal of Comparative Sociology, v. 59, n. 2, pp. 81-109, 2018.

MARCOLIN, L.; MIROUDOT, S.; SQUICCIARINI, M. The Routine Content of Occupations: New Cross-Country Measures Based on Piaac. Paris: OECD, 2016. (OECD Trade Policy Papers n. 188). Disponível em: https://www.oecd-ilibrary.org/trade/the-routine-content-of-occupations_5jm0mq86fljgen. Acesso em: 30 jan. 2020.

MATTOSO, J. Tecnologia e emprego uma relação conflituosa. São Paulo Perspec., v. 14, n. 3, pp. 115123,2000

OLIVEIRA, A. M. H. C.; CURY, E. L.; COTTA, P. S.; SANTOS, A. T. P. Evolução e desaparecimento de ocupações. Relatório Interno, 2017.

OLIVIERI, R. S. C. Tarefas profissionais e diferença salarial de gênero no Brasil. 2016. Monografia (Departamento de Economia) - Pontifícia Universidade Católica do Rio de Janeiro (PUC-RIO). Rio de Janeiro: 2016. Disponível em: http://www.econ.pucrio.br/uploads/adm/trabalhos/files/Roberta_Souza_Costa_Olivieri.pdf. Acesso em: 12 nov. 2020.

REIS, S. M. Incompatibilidades entre Educação e Ocupação: Uma Análise Regionalizada do Mercado de Trabalho Brasileiro. Tese (Doutorado em Economia) - Faculdade de Ciências Econômicas, Universidade Federal de Minas Gerais (UFMG). Belo Horizonte: 2012.

SANTOS, A. T. P.; VAZ, B. O. E.; OLIVEIRA, A. M. H. C. Evolução dos prêmios salariais relativos a habilidades ocupacionais: uma análise do período de 2006 a 2016. In: ANPEC- $47^{\circ}$ Encontro Nacional de Economia. São Paulo: 2019. Disponível em: https://en.anpec.org.br/previouseditions.php?r=encontro-2019. Acesso em: 25 jul. 2020

SEBRAE. Nota metodológica para definição dos números básicos de MPE. Brasília: 2006.

SILVA, A. M. A. Impacto de Soluções da Indústria 4.0 no Mercado de Trabalho em Portugal. 2018. Dissertação (Mestrado em Economia) - Faculdade de Economia, Universidade do Porto. Porto: 2018. 
- Fundação Instituto Capixaba de Pesquisas em Contabilidade, Economia e Finanças (FUCAPE), Vitoria, 2009. Disponível em: http://legado.fucape.br/_public/producao_cientifica/8/Dissertacao\%20Jadir\%20Soares.pdf . Acesso em: 26 jun. 2020.

SPENCE, M. Job Market Signaling. The Quarterly Journal of Economics, v. 87, n. 3, p. 355-374, 1973.

SPITZ-OENER, A. Technical Change, Job Tasks, and Rising Educational Demands: Looking Outside the Wage Structure. Journal of Labor Economics, v. 24, n. 2, p. 235-270, 2006.

SUlZBACH, V. N. Essays on Job Polarization in the Brazilian Labor Market. 2020. Tese (Doutorado em Economia) - Faculdade de Ciências Econômicas, Universidade Federal do Rio Grande do Sul (UFRGS). Porto Alegre: 2020. Disponível em: https://lume.ufrgs.br/handle/10183/213635. Acesso em: 01 dez. 2020.

TESSARINI, G.; SALTORATO, P. Impactos da Indústria 4.0 na Organização do Trabalho: Uma Revisão Sistemática da Literatura. Revista Produção Online, Florianópolis: v. 18, n. 2, p. 743-769, 2018. Disponível em: https://www.producaoonline.org.br/rpo/article/view/2967. Acesso em: 04 abr. 2019.

WEF. The Future of Jobs Report. Geneva: 2018. Disponível em: https://www.weforum.org/reports/the-future-of-jobs-report-2018. Acesso em: 25 abr. 2019.

WOOLDRIDGE, J. M. Econometric Analysis of Cross Section and Panel Data. Cambridge: The MIT Press, 2010. 